\title{
Prevalence of metabolic syndrome and its risk factors in Canadian children and adolescents: Canadian Health Measures Survey Cycle 1 (2007-2009) and Cycle 2 (2009-2011)
}

\section{MacPherson, MBA (1, 2); M. de Groh, PhD (1); L. Loukine, MSc (3); D. Prud'homme, MD (4, 5); L. Dubois, PhD (6)}

This article has been peer reviewed.

Tweet this article

\section{Abstract}

Introduction: We investigated the prevalence of metabolic syndrome (MetS) and its risk factors, and the influence of socioeconomic status, in Canadian children and adolescents.

Methods: Canadian Health Measures Survey cycle 1 (2007-2009) and cycle 2 (20092011) respondents aged 10 to 18 years who provided fasting blood samples were included ( $\mathrm{n}=1228$ ). The International Diabetes Federation (IDF) consensus definition for children and adolescents (10-15 years) and worldwide adult definition ( $\geq 16$ years) were used to diagnose MetS. Prevalence of MetS and its risk factors were calculated and differences by socioeconomic status were examined using $\chi^{2}$ tests.

Results: The prevalence of MetS was 2.1\%. One-third (37.7\%) of participants had at least one risk factor, with the most prevalent being abdominal obesity (21.6\%), low HDL-C (19.1\%) and elevated triglyceride levels (7.9\%). This combination of abdominal obesity, low HDL-C and elevated triglyceride levels accounted for $61.5 \%$ of MetS cases. Participants from households with the highest income adequacy and educational attainment levels had the lowest prevalence of one or more MetS risk factors, abdominal obesity and low HDL-C.

Conclusion: The prevalence of MetS $(2.1 \%)$ was lower than previously reported in Canada (3.5\%) and the USA (4.2\%-9.2\%), potentially due to the strict application of the IDF criteria for studying MetS. One-third of Canadian children and adolescents have at least one risk factor for MetS. Given that the risk for MetS increases with age, these prevalence estimates, coupled with a national obesity prevalence of almost $10 \%$ among youth, point to a growing risk of MetS and other chronic diseases for Canadian youth.

Keywords: Canadian Health Measures Survey, metabolic syndrome, health surveys, cardiometabolic risk factors, prevalence, adolescent, child

\section{Introduction}

Chronic diseases constitute the leading cause of preventable death in Canada and the world as well as the largest avoidable burden on the public health care system. ${ }^{1}$ The metabolic syndrome (MetS) is a constellation of cardiometabolic risk factors that are predictive for chronic disease and all-cause mortality. ${ }^{2-4}$ It is estimated that risk of cardiovascular disease (CVD) doubles and the risk of type 2 diabetes increases fivefold if MetS is present. ${ }^{3-6}$

MetS is characterized by the presence of different combinations of risk factors including obesity, hypertension, elevated fasting
Key findings

- Having metabolic syndrome (MetS) increases the risk for chronic diseasecardiovascular disease by two and type 2 diabetes by five.

- Only $2.1 \%$ of Canadian youth have MetS. However, one-third of Canadian youth have one or more risk factors for MetS.

- The biggest risk factor for MetS is abdominal obesity. As more youth are becoming obese, MetS will probably increase among Canadian youth.

- Risk of MetS increases with age. As a result, the risk for chronic diseases will probably increase as the Canadian population ages.

- Youth who live in better off or better educated households have the lowest risk for MetS.

triglycerides, insulin resistance, low total cholesterol, high low-density lipoprotein cholesterol, low high-density lipoprotein cholesterol (HDL-C), elevated apolipoprotein B, elevated C-reactive protein and elevated homocysteine. $^{7-9}$ These clinical features of MetS, if present together, tend to suggest a common etiology; the proposed mechanisms underlying MetS and its influence on health outcomes are discussed elsewhere. ${ }^{7,10,11}$

The global prevalence of obesity and diabetes has increased dramatically in the past quarter century. ${ }^{12}$ This increase, in

Author references:

1. Social Determinants and Science Integration Directorate, Public Health Agency of Canada, Ottawa, Ontario, Canada

2. Faculty of Graduate and Postdoctoral Studies, University of Ottawa, Ottawa, Ontario, Canada

3. Centre for Chronic Disease Prevention and Control, Public Health Agency of Canada, Ottawa, Ontario, Canada

4. Institut de recherche de I'Hôpital Montfort, Ottawa, Ontario, Canada

5. Faculty of Health Sciences, University of Ottawa, Ottawa, Ontario, Canada

6. Department of Epidemiology and Community Medicine, Faculty of Medicine, University of Ottawa, Ottawa, Ontario, Canada

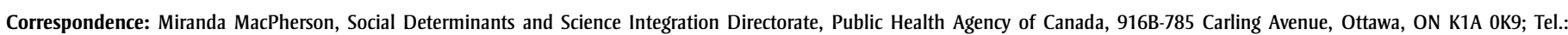
613-668-4018; Fax:613-960-0921; Email: miranda.macpherson@phac-aspc.ǵc.ca 
turn, has contributed to a higher prevalence of MetS. ${ }^{13}$ Worldwide estimates of the prevalence of MetS range from $1.2 \%$ to $22.6 \%$ for youth and $9.0 \%$ to $35.0 \%$ for adults, depending on the definition of MetS used, the region, the study design, the years of the study, and the age group and study population. ${ }^{13-16}$ In Canada, the prevalence of MetS among adults is between about $11.4 \%$ and $22.2 \%$, which is greater than the prevalence estimates of $10 \%$ to $15 \%$ measured in adults in the early 1990s. ${ }^{17-22}$ In comparison, the prevalence of MetS among adults in the USA is between about $22 \%$ and $34 \% .{ }^{23-26}$ It is widely accepted that the prevalence of MetS increases significantly with age. ${ }^{17-20,23}$ The national prevalence among youth aged 12 to 19 years is $3.5 \%$ in Canada (based on a 2012 study using the Adult Treatment Panel III criteria for MetS) and $4.2 \%$ to $9.2 \%$ in the USA, with about $42 \%$ to $63 \%$ of youth in the USA having one or more MetS risk factors. ${ }^{19,27-29}$ Further examination of national prevalence among youth will help us understand the progression of MetS and its risk factors among Canadians.

There is substantial evidence supporting an inverse relationship between socioeconomic status (SES) and CVDs, conditions that share some risk factors with MetS. ${ }^{30-32}$ Studies examining the relationship between SES and MetS reveal a similar pattern in which people with a lower social status experience a significantly higher prevalence of MetS. ${ }^{17,19,20,33,34}$ Canadian national studies have shown that the prevalence of MetS is significantly lower among people from households with postsecondary education compared to those with less education, a relationship that is particularly evident in women. ${ }^{17,19,20}$ This inverse relationship remains consistent between household income and MetS, albeit less pronounced, with Canadian households with the lowest quartiles of income having a higher prevalence of MetS than households with average and higher incomes. ${ }^{17,20}$

A challenge in determining the prevalence of MetS has been the use of multiple criteria and definitions for identifying this condition. In response, the International Diabetes Federation (IDF) released the IDF Consensus Worldwide Definition of the
Metabolic Syndrome as a single, universally accepted tool. ${ }^{35}$ The IDF defines MetS as the presence of abdominal obesity (measured by waist circumference) and 2 or more of the following risk factors: low levels of HDL-C, hypertension, elevated fasting triglyceride levels and elevated glucose concentration. ${ }^{6,36}$ Before the IDF consensus definition, the most recognized definitions were criteria established by the World Health Organization, the European Group for the Study of Insulin Resistance, and the National Cholesterol Education Program Expert Panel on Detection, Evaluation, and Treatment of High Blood Cholesterol in Adults (Adult Treatment Panel III criteria) (NCEP ATP III). ${ }^{9,37,38}$

Diagnosing MetS among children and adolescents proves particularly challenging given the difficulty in establishing accurate, meaningful and harmonized criteria for this population. Consequently, prevalence estimates of MetS among children and youth vary greatly depending on the adopted definition. ${ }^{8}$ In 2007, the IDF released their Consensus Definition of the Metabolic Syndrome in Children and Adolescents. ${ }^{36}$ This criterion provides an ageand sex-specific definition for youth aged 10 to 15 years. The IDF definition further stipulates that the worldwide adult definition of MetS should be applied for individuals aged 16 years or older and that MetS should not be diagnosed in children less than 10 years old. ${ }^{36}$

The main objectives of this study were to investigate the prevalence of MetS and its risk factors, and the influence of SES on these risk factors, in Canadian children and adolescents (10-18 years) using nationally representative data from the Canadian Health Measures Survey (CHMS). This study builds upon an earlier national analysis of Canadian youth

- by including those aged 10 and 11 years;

- by calculating the prevalence of one or more risk factors for MetS among youth;

- by examining the patterns of risk presentation; and

- by using data from two cycles of the CHMS. ${ }^{19}$

This is the first national study to strictly apply the IDF consensus definition of MetS in children and adolescents, the most current and universally accepted definition of MetS for youth; and to use Canadian age- and sex-specific waist circumference reference data to determine abdominal obesity in Canadian children and youth.

\section{Methods}

\section{Data source}

The CHMS is a nationally representative survey designed to collect information on the health of Canadians. ${ }^{39-41}$ Conducted by Statistics Canada, the CHMS consists of an in-home interview and a physical assessment conducted at a mobile examination centre. The interview collects demographic, socioeconomic, family history and general health information. The physical assessment includes measures of anthropometry, spirometry, blood pressure, fitness and oral health and involves collecting biological specimens. ${ }^{39-41}$ The survey covered Canadians living at home in the 10 provinces and 3 territories, although people living on reserves and other Aboriginal settlements, in institutions and in certain remote regions as well as full-time members of the Canadian Forces were excluded. ${ }^{39-41}$ The CHMS cycle 1 (2007-2009) collected data on people aged 6 to 79 years, with cycle 2 (2009-2011) expanding to cover those aged 3 to 79 years. ${ }^{39-41}$ In total, this represents $96.3 \%$ of the Canadian population. ${ }^{39-41}$

The CHMS produces reliable estimates at the national level by age group and sex through a multistage sampling strategy. ${ }^{39-42}$ The selection of collection sites was informed by the Labour Force Survey sampling frame. A multitude of practices were used to minimize non-response; the combined response rate for home and clinic visits was $51.7 \%$ for cycle 1 and $55.5 \%$ for cycle 2. ${ }^{39-42}$ Statistics Canada calculated the sampling weights by multiplying the selection weights for collection sites by the selection weights for dwellings, followed by a series of adjustments for non-response at the initial, interview and MEC stage. ${ }^{42}$

\section{Study population}

All 10- to 18-year-old CHMS respondents who provided fasting blood samples for 
cycle 1 (2007-2009) or cycle 2 (2009-2011) were included ( $\mathrm{n}=1228$ ). No participants were pregnant. Sample weights specific to the fasting subgroup were provided by Statistics Canada to ensure appropriate representativeness at the population level.

\section{Criteria for diagnosing MetS}

We applied the IDF consensus definition of MetS for children and adolescents to participants aged 10 to 15 years and the IDF worldwide adult definition adult criteria to participants aged 16 to 18 years.

The IDF consensus definition for children and adolescents defines MetS as having abdominal obesity (waist circumference equal or greater than the $90^{\text {th }}$ percentile by age and sex) and the presence of two or more of the following clinical features: elevated triglycerides $(\geq 1.7 \mathrm{mmol} / \mathrm{L})$; low HDL-C $(<1.03$ $\mathrm{mmol} / \mathrm{L}$ ); high blood pressure (systolic $\geq 130 \mathrm{~mm} \mathrm{Hg}$ and/or diastolic $\geq 85 \mathrm{~mm} \mathrm{Hg}$ and/or diagnosis of hypertension); and elevated glucose ( $\geq 5.6 \mathrm{mmol} / \mathrm{L}$ and/or diagnosis of type 2 diabetes). ${ }^{36}$

The IDF worldwide adult criteria define MetS as having abdominal obesity and the presence of two or more of the following clinical features: high triglycerides $(\geq 1.7 \mathrm{mmol} / \mathrm{L})$, low HDL-C $(<1.03 \mathrm{mmol} / \mathrm{L}$ in males and $<1.29 \mathrm{mmol} / \mathrm{L}$ in females); high blood pressure (systolic $\geq 130 \mathrm{~mm} \mathrm{Hg}$ and/or diastolic $\geq 85 \mathrm{~mm} \mathrm{Hg}$ and/or diagnosis of hypertension); and high glucose ( $\geq 5.6 \mathrm{mmol} / \mathrm{L}$ and/ or diagnosis of type 2 diabetes). ${ }^{35}$

We defined abdominal obesity using the $90^{\text {th }}$ percentiles from the age- and sex-specific waist circumference reference data established from the 1981 Canadian Fitness Survey. ${ }^{43}$ We applied the waist circumference cut-offs for 11-year-olds to those aged 10 to 11 years since this reference provided estimates for those aged 11 to 18 years only.

\section{Variables for assessing demographic and socioeconomic status}

A respondent's demographic and SES was assessed through the variables of household educational attainment, household income adequacy, Aboriginal status, and immigrant status. The use of household education and household income variables in this study is consistent with previous studies examining the relationship between SES and MetS. ${ }^{17,19,20,26}$ Education is the most frequently used indicator of SES in epidemiological studies and, among indicators of SES, it tends to have the strongest and most consistent relationship with cardiovascular health. ${ }^{20,31,44}$ Household income is another well-established SES indicator and determinant of health. ${ }^{44-48}$ Statistics Canada calculated income adequacy by classifying each participant into categories based on total household income from all sources and the number of people living in the household. ${ }^{39,40}$

To allow for greater statistical power, we reclassified both the household educational attainment and income adequacy variables from 4 categories into 3. For income adequacy, we combined the "lowest income", and "lower middle income" categories, resulting in "lowest and lower middle," "upper middle" and "highest" categories. For household educational attainment, we combined the "less than secondary school graduation" and "secondary school graduation" categories, resulting in "secondary school graduation or less," "some postsecondary” and “postsecondary graduation” categories.

\section{Statistical analysis}

We conducted statistical analyses using SAS version 9.3 (SAS Institute Inc., Cary, NC, US) for data manipulation and variance estimation using the bootstrap method. ${ }^{49}$ The prevalence of MetS and each risk factor were estimated and expressed as a frequency and a percentage with a $95 \%$ confidence interval $(\mathrm{CI}) \cdot \chi^{2}$ tests were used to examine differences in MetS, and each risk factor by gender, Aboriginal status, immigrant status, household education and income adequacy. The analyses were conducted using weighting and bootstrapping. Statistical significance was set at a $p$ value of less than .05 .

We obtained ethics approval for this project from the University of Ottawa's Research Ethics Board.

\section{Results}

\section{Description of study sample}

To be able to evaluate the criteria for MetS, of the original sample of child and adolescent respondents aged 10 to 18 years, we included in our study only those participants who provided fasting blood samples. This resulted in a final sample of 1228 participants. The sample included slightly more males $(51.5 \%)$ than females $(48.5 \%)$.

Table 1 shows an overview of the sample by demographic and SES.

\section{Prevalence of MetS}

Only 25 study participants were diagnosed with MetS, which represents $2.1 \%$ of participants (95\% CI: $0.8-3.3)^{*}$ (Table 2). This small number of participants with MetS prevented accurate disaggregation by sex, age or SES.

\section{Prevalence of individual risk factors}

Over one-third (37.7\%; 95\% CI: 33.8-41.6) of children and adolescents had at least one of the clinical features of MetS (1 or more risk factors) (Table 2). Risk factors in order of prevalence were abdominal obesity (21.6\%; 95\% CI: 16.6-26.7), low HDL-C (19.1\%; 95\% CI: 16.6-21.8), elevated triglycerides (7.9\%; 95\% CI: 4.8-11.0) and elevated glucose $(1.7 \% \text {; } 95 \% \mathrm{CI}: 0.7-2.8)^{\dagger}$. The prevalence of elevated blood pressure was too low to provide an accurate statistical estimate. There were no gender differences for the prevalence of each risk factor.

\section{Pattern of risk factor combinations}

The most prevalent single risk factors were abdominal obesity (10.7\%), low HDL-C (9.8\%) and elevated triglycerides (2.7\%) (Table 3). The most prevalent distinct combinations of two risk factors were abdominal obesity coupled with low HDL-C (5.1\%) and abdominal obesity and elevated triglycerides (1.5\%). Among distinct combinations of three risk factors, the most prevalent combination was abdominal obesity, low HDL-C

"This result is published with caution due to a coefficient of variation (CV) of 29.0.

†Due to small cell sizes, not all risk factors and SES categories could be reported. 
TABLE 1

Sample profile, 10-18 years $^{\mathrm{a}}$

\begin{tabular}{|c|c|c|}
\hline Characteristics & Study sample, $n$ & Percentage of study sample, \% \\
\hline \multicolumn{3}{|l|}{ Demographic profile $(n=1228)$} \\
\hline \multicolumn{3}{|l|}{ Sex } \\
\hline Male & 632 & 51.5 \\
\hline Female & 596 & 48.5 \\
\hline \multicolumn{3}{|l|}{ Age, years } \\
\hline 10 & 172 & 14.0 \\
\hline 11 & 184 & 15.0 \\
\hline 12 & 127 & 10.3 \\
\hline 13 & 151 & 12.3 \\
\hline 14 & 115 & 9.4 \\
\hline 15 & 117 & 9.5 \\
\hline 16 & 131 & 10.7 \\
\hline 17 & 121 & 9.8 \\
\hline 18 & 110 & 9.0 \\
\hline \multicolumn{3}{|l|}{ Socioeconomic profile } \\
\hline \multicolumn{3}{|l|}{ Income adequacy $(n=1178)$} \\
\hline Lowest and lower middle & 247 & 19.7 \\
\hline Upper middle & 333 & 25.8 \\
\hline Highest & 598 & 50.4 \\
\hline \multicolumn{3}{|l|}{ Household education $(n=1193)$} \\
\hline Secondary school graduation or less & 126 & 11.0 \\
\hline Some postsecondary & 81 & 6.4 \\
\hline Postsecondary graduation & 986 & 78.3 \\
\hline \multicolumn{3}{|l|}{ Aboriginal origin or identity $(n=1227)$} \\
\hline Aboriginal & 46 & 4.4 \\
\hline Not Aboriginal & 1181 & 95.5 \\
\hline \multicolumn{3}{|l|}{ Immigrant status } \\
\hline Immigrant & 120 & 10.2 \\
\hline Not immigrant & 1108 & 89.8 \\
\hline
\end{tabular}

${ }^{\mathrm{a}}$ Figures are based on raw data.

and elevated triglycerides (1.3\%). This combination of three risk factors accounted for $61.5 \%$ of MetS cases (Table 3 ).

\section{Associations between SES (household educational attainment and income adequacy) and risk factors}

Participants from families with the highest incomes had the lowest percentage of one or more risk factor(s) $(35.5 \%$; $95 \%$ CI: $29.8-$ $41.2)$, abdominal obesity $(18.4 \%$; $95 \% \mathrm{CI}$ : 11.7-25.1) and low HDL-C (17.5\%; $95 \% \mathrm{CI}$ : 14.2-20.6) versus those from families with the lowest and lower middle incomes (Table 4). Educational attainment results showed that participants with a household member with postsecondary graduation had the lowest percentage of one or more risk factor(s) (35.3\% ; 95\% CI: 31.0-39.6), abdominal obesity (19.8\%; 95\% CI: 14.6-25.0) and low HDL-C (17.5\%; 95\% CI: 14.8-20.2) versus those from households with some postsecondary education or secondary school graduation or less. Due to small cell sizes, the results could not be disaggregated by Aboriginal or immigrant status.

\section{Discussion}

The prevalence for MetS among children and adolescents (2.1\%) was lower than previously reported in Canada (3.5\%) and the USA (4.2\%-9.2\%). ${ }^{19,27-29}$ Assuming our sample is representative of the Canadian population, this prevalence of $2.1 \%$ would be equivalent to about 64832 children and adolescents. The prevalence of one or more risk factors (37.7\%) among children and adolescents was also lower than reported in the USA $(42 \%-63 \%) .^{28}$ In comparison to earlier national estimates on Canadian youth, our study's lower prevalence may be attributed to our applying the IDF definition of MetS, which has slightly more stringent criteria, including the required presence of abdominal obesity. ${ }^{19,43,50,51}$ Furthermore, MetS is known to increase with age and our sample included younger ages (10-11 years) and had greater numbers of younger participants ( $\mathrm{n}=356$ for $10-11$ years) than older, adolescent participants ( $\mathrm{n}=231$ for $17-18$ years $)^{17,23}$

The lower prevalence estimates we found compared to those in the USA may be attributable to several factors. Obese youth have a higher prevalence of MetS than do those of normal weight and the prevalence of obesity among youth is higher in the USA than in Canada. ${ }^{52-54}$ The prevalence estimates in the USA were calculated using data from the National Health and Nutrition Examination Survey with variation in the periods of data collection (ranging from 1988-2006), the MetS definition (all variations of ATP III) and criteria for abdominal obesity. Our study followed a strict application of the IDF MetS definition including age- and sex-specific cut-offs. Finally, our study does not include Canadian residents living on reserve or in other Aboriginal settlements, populations shown to have a higher prevalence of MetS. ${ }^{55-57}$

Despite the overall low prevalence of MetS, note that one-third $(37.7 \%)$ of study participants had at least one risk factor for MetS. This finding, coupled with a prevalence of obesity of almost $10 \%$ among Canadian children and youth, is disconcerting as the probability of MetS also increases with obesity. ${ }^{26}$ Further, given that age is one of the most significant predictors for MetS, it is reasonable to assume that children and adolescents with one or more risk factors are more susceptible to MetS and, correspondingly, chronic disease as adults. ${ }^{2-4}$ Evidence indicates that, in the long term, adults with MetS have an elevated risk of CVD-attributed mortality, although a moderate-to-high level of cardiorespiratory fitness has been shown to mitigate some of this risk. ${ }^{53,58}$ 
TABLE 2

Prevalence of metabolic syndrome and risk factors ${ }^{\mathrm{a}}, 10-18$ years $^{\mathrm{a}}(\mathrm{n}=1228)$

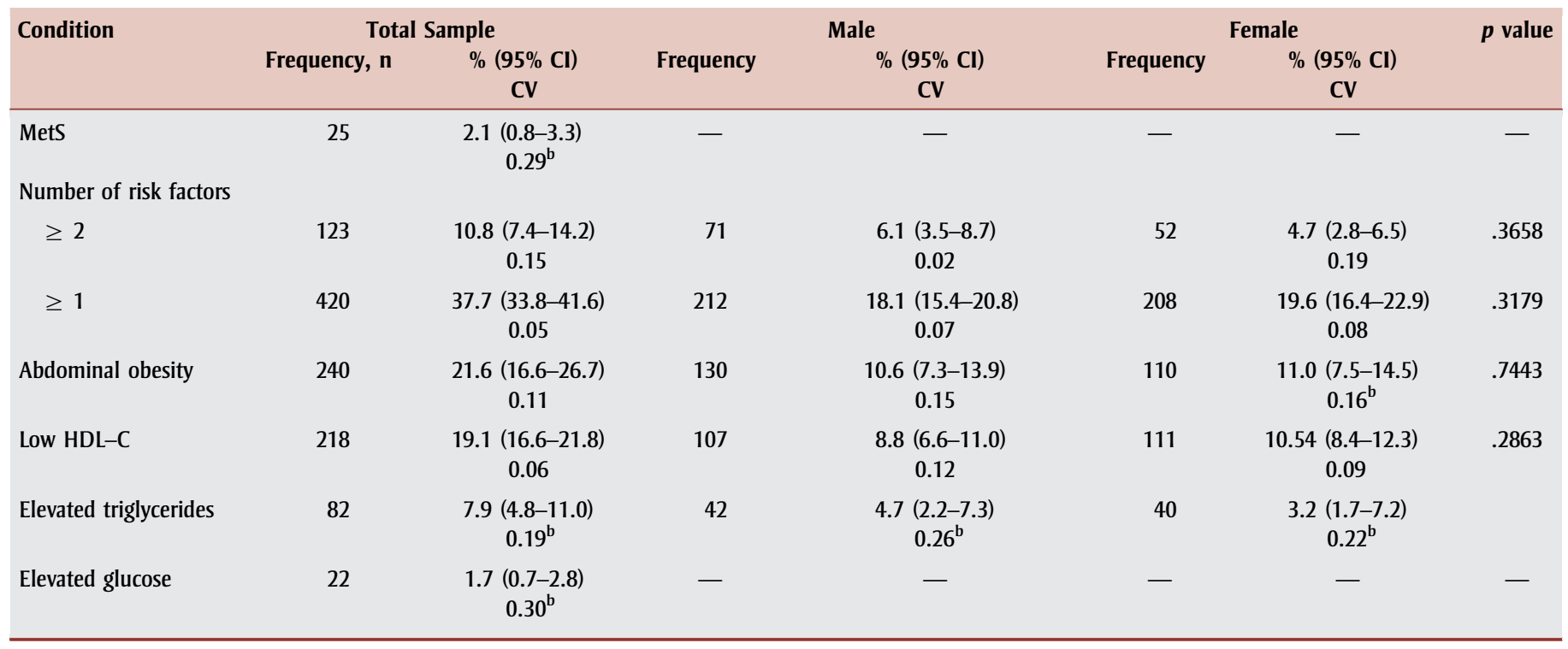

Abbreviations: BP, blood pressure; CV, coefficient of variation; HDL-C, high-density lipoprotein cholesterol.

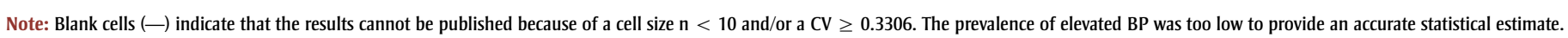

${ }^{\mathrm{a}}$ These figures are based on weighted data.

${ }^{\mathrm{b}}$ These figures are published with reservation as $0.16 \leq \mathrm{CV} \geq 0.33$.

Our findings support the conclusions of previous studies that abdominal obesity, low HDL-C and elevated triglycerides are the most prevalent risk factors of MetS among children and adolescents; ${ }^{28}$ in fact, this combination accounted for $61.5 \%$ of all MetS cases in this study. The most prevalent risk factor was abdominal obesity (21.6\%), which may be attributed to over one-quarter of Canadian youth being overweight or obese. ${ }^{59}$ The IDF considers abdominal obesity as a prerequisite for MetS given that it is associated with an increased risk of cardiovascular disease and an independent predictor of insulin resistance, lipid levels and high blood pressure. ${ }^{35,36,60}$ Our study defined abdominal obesity using age- and sex-specific reference data established from the 1981 Canadian Fitness Survey $\left(90^{\text {th }}\right.$ percentile).$^{43}$ Domestic prevalence estimates of obesity among youth have almost doubled in the past 25 years, meaning that these predefined cut-offs represent norms for the Canadian population before this dramatic increase in body fat. ${ }^{59,61}$

Consistent with previous studies on youth, hypertension is not highly prevalent in the early onset of this syndrome. ${ }^{28}$

Participants from families in the highest income adequacy and household educational attainment groups had the lowest prevalence of one or more risk factors, abdominal obesity and low HDL-C, which is consistent with earlier findings between SES and MetS risk factors. ${ }^{17,19,20,62}$ For abdominal obesity, a dose-response relationship was present for household education. The relationship between household education and prevalence of risk factors appeared to be more sensitive than household income, which is also consistent with previous findings. ${ }^{17,20,62}$ This may be attributed to the influence of education on health literacy and behaviour, such as nutrition and physical activity, which are related to abdominal obesity and MetS. ${ }^{22,63}$ Further, household education is considered

TABLE 3

Pattern of metabolic syndrome risk factor combinations ${ }^{\mathrm{a}}$

\begin{tabular}{|c|c|}
\hline Risk factor combination $(\mathrm{n}=1228)$ & Frequency $(\%)$ \\
\hline \multicolumn{2}{|l|}{ Presence of 1 risk factor } \\
\hline Abdominal obesity & $131(10.7)$ \\
\hline Low HDL-C & $121(9.8)$ \\
\hline Elevated TG & $33(2.7)$ \\
\hline \multicolumn{2}{|l|}{ Presence of 2 risk factors } \\
\hline Abdominal obesity + low HDL-C & $63(5.1)$ \\
\hline Abdominal obesity + elevated TG & $19(1.5)$ \\
\hline \multicolumn{2}{|l|}{ Presence of 3 risk factors } \\
\hline Abdominal obesity + low HDL-C + elevated TG & $16(1.3)$ \\
\hline Risk factor combination in participants with MetS $(n=26)$ & Frequency $(\%)$ \\
\hline \multicolumn{2}{|l|}{ Presence of 3 risk factors } \\
\hline Abdominal obesity + low HDL-C + elevated TG & $16(61.5)$ \\
\hline
\end{tabular}

Abbreviations: HDL-C, high-density lipoprotein cholesterol; TG, triglycerides.

Note: Risk factor combinations with cell sizes $\mathrm{n}<\mathbf{1 0}$ were not published as prevalence were too low to provide accurate statistical estimates. ${ }^{\mathrm{a}}$ These figures are based on weighted data. 
TABLE 4

Relationship between metabolic syndrome risk factors and socioeconomic status, fasting sub-sample ages $10-18$ years $^{\mathrm{a}}$

\begin{tabular}{|c|c|c|c|}
\hline Condition & $\begin{array}{c}\text { Presence of } \geq 1 \text { risk } \\
\text { factor }(\mathbf{s}) \\
\%(95 \% \mathrm{Cl}) \\
\text { CV }\end{array}$ & $\begin{array}{c}\text { Abdominal obesity } \\
\qquad \begin{array}{c}(95 \% \mathrm{Cl}) \\
\text { CV }\end{array}\end{array}$ & $\begin{array}{l}\text { Low HDL-C } \\
\begin{array}{l}\text { \% }(95 \% \mathrm{CI}) \\
\text { CV }\end{array}\end{array}$ \\
\hline \multicolumn{4}{|l|}{ Income Adequacy (50 missing) } \\
\hline Lowest and lower middle & $\begin{array}{c}35.9(25.9-46.0) \\
0.14\end{array}$ & $\begin{array}{c}21.4(11.8-30.9) \\
0.22^{\mathrm{b}}\end{array}$ & $\begin{array}{c}19.4(12.7-26.1) \\
0.17^{\mathrm{b}}\end{array}$ \\
\hline Upper middle & $\begin{array}{c}41.8(34.4-49.3) \\
0.09\end{array}$ & $\begin{array}{c}28.1(19.7-36.6) \\
0.15\end{array}$ & $\begin{array}{c}20.2(15.2-25.2) \\
0.12\end{array}$ \\
\hline Highest & $\begin{array}{c}35.5(29.8-41.2) \\
0.08\end{array}$ & $\begin{array}{c}18.4(11.7-25.1) \\
0.17^{b}\end{array}$ & $\begin{array}{c}17.5(14.2-20.6) \\
0.09\end{array}$ \\
\hline \multicolumn{4}{|l|}{ Household education (35 missing) } \\
\hline Secondary school graduation or less & $\begin{array}{c}43.7(29.4-58.0) \\
0.16\end{array}$ & $\begin{array}{c}31.8(17.6-46.1) \\
0.22^{\mathrm{b}}\end{array}$ & $\begin{array}{c}19.3(6.9-31.7) \\
0.31^{\mathrm{b}}\end{array}$ \\
\hline Some postsecondary & $\begin{array}{c}42.8(32.4-53.2) \\
0.12\end{array}$ & $\begin{array}{c}28.3(13.7-42.9) \\
0.25^{\mathrm{b}}\end{array}$ & $\begin{array}{c}26.1(15.1-37.3) \\
0.21^{\mathrm{b}}\end{array}$ \\
\hline Postsecondary graduation & $\begin{array}{c}35.3(31.0-39.6) \\
0.06\end{array}$ & $\begin{array}{c}19.8(14.6-25.0) \\
0.13\end{array}$ & $\begin{array}{c}17.5(14.8-20.2) \\
0.08\end{array}$ \\
\hline
\end{tabular}

Abbreviations: BP, blood pressure; HDL-C, high-density lipoprotein cholesterol; SES, socioeconomic status.

Note: Small cell sizes prohibited further analysis of BP, glucose and triglyceride risk factors and Aboriginal and immigrant status SES factors.

${ }^{\mathrm{a}}$ These figures are based on weighted data.

${ }^{\mathrm{b}}$ These figures are being published with reservation as $0.16 \leq \mathrm{CV} \geq 0.33$.

to be more stable, and less influenced by health status, than household income over the life course. ${ }^{30}$ More broadly, participants from households with lower education and income levels are more likely to experience unfavourable social, physical and economic environments that can contribute to poorer health outcomes, including a higher rate of mortality attributed to CVDs. ${ }^{30,47}$ These results point to a need for interventions, including public policy, public education, research and medical care, that focus on mitigating the impact of lower levels of education and income on health outcomes. Research focussed on elucidating the causal pathways through which SES influences the risk for MetS and CVDs throughout the life course would be useful in designing effective, targeted interventions.

Future studies using more cycles of CHMS data may have the statistical power with which to examine MetS and its risk factors in Canadian children and adolescents in greater detail. The sex differences in MetS in relation to SES should be examined to better understand the sex-specific ways in which unfavourable socioeconomic conditions affect MetS outcomes. Further, regression analyses are needed to comprehensively examine the relationship between MetS, its risk factors, behaviour such as physical activity and sleep, and SES.

\section{Strengths}

This is the first national study to apply the IDF consensus definition of MetS to children and adolescents and to use Canadian ageand sex-specific waist circumference reference data for determining abdominal obesity to Canadian children and youth. Strictly applying the IDF criteria for studying MetS at the population level in Canada will allow for more accurate comparisons with future studies on MetS in children and adolescents.

This study was conducted using government survey data that is both high quality and representative of $96 \%$ of Canadians.

\section{Limitations}

Descriptive statistics was the only method we could use to examine MetS using this dataset of Canadian children and adolescents because the sample size was small; only those participants from whom fasting blood samples were taken were included. The sample size and low prevalence of MetS did not allow for an analysis of the relationship between each risk factor and MetS. The small sample size also prohibited a robust statistical analysis of the influence of demographic and SES variables on MetS and allowed only limited analysis of the influence of these variables on risk factors with no distinction by sex. It was not feasible to disaggregate by sex, age, Aboriginal status or immigrant status. Furthermore, the cross-sectional design of the CHMS limits inference about causal pathways underlying the observed relationships. Consequently, the study focussed on the prevalence of each MetS risk factor.

Nonetheless, the study results improve the understanding of the current landscape of cardiometabolic risks among Canadian children.

\section{Conclusions}

By investigating the prevalence of MetS and its risk factors among Canadian children and adolescents, this study highlights important health and socioeconomic considerations for Canada's child and adolescent population. The results affirm previous findings of a low prevalence of MetS among youth. The results also highlight important indicators of future health risk among Canadian youth by showing that one in three have at least one risk factor for MetS, one in five have abdominal obesity, and one in five have low HDL-C. Efforts to prevent, diagnose and treat MetS and its risk factors among youth are important to prevent type 2 diabetes, cardiovascular diseases and premature mortality.

\section{Acknowledgements}

We are grateful to Statistics Canada for conducting the Canadian Health Measures Survey and to the people of Canada who participated in the study.

\section{There were no competing interests.}

We acknowledge the support of the University of Ottawa's Department of Epidemiology 
and Community Medicine and the Public Health Agency of Canada.

\section{References}

1. Public Health Agency of Canada. Working together globally: Canada's World Health Organization (WHO) Collaborating Centre on Chronic Non-communicable Disease Policy [Internet]. Ottawa (ON): Public Health Agency of Canada; 2012 Sep 7; [cited 2014 Feb 1]. Available from: http://www.phacaspc.gc.ca/about_apropos/whocc-ccoms/ index-eng.php

2. Ford ES. Risks for all-cause mortality, cardiovascular disease, and diabetes associated with the metabolic syndrome: a summary of the evidence. Diabetes Care. 2005;28(7):1769-78.

3. Isomaa A, Almgren $\mathrm{P}$, Tuomi $\mathrm{T}$, et al. Cardiovascular morbidity and mortality associated with the metabolic syndrome. Diabetes Care. 2001;24(4):683-9.

4. McNeill AM, Rosamond WD, Girman CJ, et al. The metabolic syndrome and 11-year risk of incident cardiovascular disease in the Atherosclerosis Risk in Communities study. Diabetes Care. 2005;28(2)385-90.

5. Haffner SM, Valdex RA, Hazuda HP, Mitchell BD, Morales PA, Stern MP. Prospective analysis of the insulin resistance syndrome (Syndrome X). Diabetes. 1992;41(6): 715-22.

6. Alberti KG, Zimmet PZ, Shaw J. Metabolic syndrome - a new world-wide definition. Lancet. 2005;366(9491):1059-62.

7. Huang TT, Ball GD, Franks PW. Metabolic syndrome in youth: current issues and challenges. Appl Physiol Nutr Metab. 2007; 32(1):13-22.

8. Haffner SM. The metabolic syndrome: inflammation, diabetes mellitus, and cardiovascular disease. Am J Cardiol. 2006;97(2A): 3A-11A.

9. Alberti KG, Zimmet PZ. Definition, diagnosis and classification of diabetes mellitus and its complications, part 1: provisional report of a WHO consultation. Diabetes Med. 1998;15(7):539-53.
10. Reaven GM. Role of insulin resistance in human disease. Diabetes. 1988;37(12): 1595-607.

11. Dandona P, Aljada A, Chaudhuri A, Mohanty P, Garg R. Metabolic syndrome: a comprehensive perspective based on interactions between obesity, diabetes and inflammation. Circulation. 2005;111(11): 1448-54.

12. Zimmet P, Alberti KG, Shaw J. Global and societal implications of the diabetes epidemic. Nature. 2001;414:782-7.

13. Eckel RH, Grundy SM, Zimmet PZ. The metabolic syndrome. Lancet. 2005;364(9468): 1415-28.

14. Goodman E, Daniels SR, Morrison JA, Huang B, Dolan LM. Contrasting prevalence of and demographic disparities in the world health organization and national cholesterol education program adult treatment panel III definitions of metabolic syndrome among adolescents. J Pediatr. 2004;4(59): 445-51.

15. Tailor AM, Peeters PH, Norat T, Vineis $P$, Romaquera D. An update on the prevalence of the metabolic syndrome in children and adolescents. Int J Pediatr Obes. 2010;5(3): 202-13.

16. Cameron AJ, Shaw JE, Zimmet PZ. The metabolic syndrome: prevalence in worldwide populations. Endocrinol Metab Clin North Am. 2004;33(2):351-75.

17. Riediger ND, Clara I. Prevalence of metabolic syndrome in the Canadian adult population. CMAJ. 2011;183(15):E1127-34.

18. Statistics Canada. Health Fact Sheets Metabolic syndrome in Canada: 2009-2011. Ottawa (ON): Statistics Canada; 2012 [Statistics Canada, Catalogue No.: 82-625-X].

19. Setayeshgar S, Whiting SJ, Vatanparast H. Metabolic syndrome in Canadian adults and adolescents: prevalence and associated dietary intake. ISRN Obesity. 2012;2012:1-8.

20. Ardern CI, Katzmarzyk PT. Geographic and demographic variation in the prevalence of the metabolic syndrome in Canada. Can J Diabetes. 2007;31(1):34-46.
21. Brenner D, Arora P, Karmali M, Badawi A. The impact of the metabolic syndrome on cardiometabolic and inflammatory profiles among Canadian adults. J Epidemiol Community Health. 2011;65(A):A228-9.

22. Brien SE, Katzmarzyk PT. Physical activity and the metabolic syndrome in Canada. Appl Physiol Nutr Metab. 2006;31(1):40-7.

23. Ford ES, Giles WH, Mokdad AH. Increasing prevalence of the metabolic syndrome among US adults. Diabetes Care. 2004;27(10): 2444-9.

24. Ervin RB. Prevalence of metabolic syndrome among adults 20 years of age and over, by sex, age, race and ethnicity, and body mass index: United States, 2003-2006. Natl Health Stat Report. 2009;13:1-7.

25. Ford ES, Giles WH, Dietz WH. Prevalence of the metabolic syndrome among US adults: findings from the third National Health and Nutrition Examination Survey. JAMA. 2002; 287(3):356-9.

26. Park YW, Zhu S, Palaniappan L, Heshka S, Carnethon MR, Heymsfield SB. The metabolic syndrome: prevalence and associated risk factor findings in the US population from the third National Health and Nutrition Examination Survey, 1988-1994. Arch Intern Med. 2003;163(4):427-36.

27. De Ferranti SD, Gauvreau K, Ludwig DR, Neufeld EJ, Newburger J, Rifai N. Prevalence of the metabolic syndrome in American adolescents: findings from the third National Health and Nutrition Examination Survey. Circulation. 2004;110(16):2494-7.

28. Johnson WD, Kroon JJ, Greenway FL, Bouchard C, Ryan D, Katzmarzyk PT. Prevalence of risk factors for metabolic syndrome in adolescents: National Health and Nutrition Examination Survey (2001-2006). Arch Pediatr Adolesc Med. 2009;163(4): 371-7.

29. Cook S, Weitzman M, Auinger P, Nguyen M, Dietz WH. Prevalence of a metabolic syndrome phenotype in adolescents: findings from the third National Health and Nutrition Examination Survey, 1988-1994. Arch Pediatr Adolesc Med. 2003;157(8): 821-7. 
30. Kaplan GA, Julian E. Socioeconomic factors and cardiovascular disease: a review of the literature. Circulation. 1993;88(4):1973-98.

31. Marmot M. Income inequality, social environment, and inequalities in health. J Policy Anal Manage. 2001;20(1):156-9.

32. Hemingway $H$, Shipley $M$, Macfarlane $P$, Marmot M. Impact of socioeconomic status on coronary mortality in people with symptoms, electrocardiographic abnormalities, both or neither: the original Whitehall study 25 year follow up. J Epidemiol Community Health. 2000;54(7):510-6

33. Brunner EJ, Marmot MG, Nanchahal K, et al. Social inequality in coronary risk: central obesity and the metabolic syndrome, evidence from the Whitehall II study. Diabetologia. 1997;40(11):1341-9.

34. Santos AC, Ebrahim S, Barros H. Gender, socio-economic status and metabolic syndrome in middle-aged and old adults. BMC Public Health. 2008;8:62.

35. International Diabetes Federation. The IDF consensus worldwide definition of the metabolic syndrome [Internet] Brussels: IDF Communications; 2006 [cited 2014 Sep 10]. Available from: http://www.idf.org/webdata/ docs/IDF_Meta_def_final.pdf

36. International Diabetes Federation. The IDF consensus definition of the metabolic syndrome in children and adolescents [Internet] Brussels: IDF Communications; 2007 [cited 2014 Sep 10]. Available from: http:// www.idf.org/webdata/docs/Mets_definition_ children.pdf

37. Balkau B, Charles MA. Comment on the provisional report from the WHO consultation, European Group for the Study of Insulin Resistance. Diabetes Med. 1999 May;16(5):442-3.

38. National Heart Lung and Blood Institute, National Cholesterol Education Program Expert Panel on Detection Evaluation and Treatment of High Blood Cholesterol in Adults. Third report of the National Cholesterol Education Program Expert Panel on detection, evaluation, and treatment of high blood cholesterol in adults (adult treatment panel III). Circulation. 2002 Dec;106(25): 3143-421.
39. Statistics Canada. Canadian Health Measures Survey - Data User Guide: Cycle 2 [Internet] Ottawa (ON): Statistics Canada. 2013 April [cited 2013 Oct 1]. Available from: http://www23.statcan.gc.ca/imdb-bmdi/ document/5071_D2_T1_V2-eng.htm

40. Statistics Canada. Canadian Health Measures Survey - Data User Guide: Cycle 1 [Internet] Ottawa: Statistics Canada. 2011 April [cited 2013 Oct 1]. Available from: http://www23. statcan.gc.ca/imdb-bmdi/document/5071_D2_ T1_V1-eng.htm

41. Tremblay MS, Gorber SC. Canadian Health Measures Survey: Brief Overview. C J Public Health. 2007 Nov-Dec;98(6):453-6.

42. Giroux S. Canadian Health Measures Survey: sampling strategy overview. Ottawa (ON): Statistics Canada; 2007 [Statistics Canada Health Reports: 18(82-003-S):31-6].

43. Katzmarzyk PT. Waist circumference percentiles for Canadian youth 11-18 years of age. Eur J Clin Nutr. 2004 Jul;58(7):1011-5.

44. Winkleby MA, Jatulis DE, Frank E, Fortmann SP. Socioeconomic status and health: how education, income, and occupation contribute to risk factors for cardiovascular disease. Am J Public Health. 1992 Jun;82(6):816-20.

45. Liberatos P, Link BG, Kelsey JL. The measurement of social class in epidemiology. Epidemiol Rev. 1988 Jan;10(1):87-121.

46. Duncan GJ, Daly MC, McDonough P, Williams DR. Optimal Indicators of socioeconomic status for health research. Am J Public Health. 2002 Jul;92(7):1151-7.

47. Commission on Social Determinants of Health. Closing the Gap in a Generation: Health Equity through Action on the Social Determinants of Health - Final Report of the Commission on Social Determinants of Health. World Health Organization (Switzerland);2008.

48. McIntosh $\mathrm{CN}$, Finès $\mathrm{P}$, Wilkins $\mathrm{R}$, Wolfson MC. Income disparities in health-adjusted life expectancy for Canadian adults, 1991 to. 2001. Ottawa (ON): Statistics Canada; 2009 [Statistics Canada Health Reports, No: 20(4): 55-64].

49. Efron B, Tibshirani R. Bootstrap methods for standard errors, confidence intervals, and other measures of statistical accuracy. Statist Sci. 1986 Feb;1(2):54-75.
50. Jolliffe CJ, Janssen I. Development of agespecific adolescent metabolic syndrome criteria that are linked to the Adult Treatment Panel III and International Diabetes Federation criteria. J Am Coll Cardiol. 2007 Feb;49(8):891-8.

51. Kassi E, Pervanidou P, Kaltsas G, Chrousos G. Metabolic syndrome: definitions and controversies. BMC Med. 2011 May:9(48):1-13.

52. Weiss R, Dziura J, Burgert TS, et al. Obesity and the metabolic syndrome in children and adolescents. New Engl J Med. 2004 Jun; 350:2362-74.

53. Katzmarzyk PT, Church TS, Janssen I, Ross R, Blair SN. Metabolic syndrome, obesity, and mortality: impact of cardiorespiratory fitness. Diabetes Care. 2005 Feb;28(2):391-7.

54. Lee S, Bacaha F, arslanian SA. Waist circumference, blood pressure, and lipid components of the metabolic syndrome. J Pediatr. 2006 Dec;49(6):809-16.

55. Pollex RL, Hanley AJ, Zinman, Harris SB, Khan HM, Hegele RA. Metabolic syndrome in Aboriginal Canadians: Prevalence and genetic association. Atherosclerosis. 2006 Jan;184(1):121-9.

56. Liu J, Young TK, Zinman B, Harris SB, Connelly PW, Hanley AJ. Lifestyle variables, non-traditional cardiovascular risk factors, and the metabolic syndrome in an Aboriginal Canadian population. Obesity (Silver Spring). 2005 Mar;14(3):500-8.

57. Kaler SN, Ralph-Campbell K, Pohar S, King M, Laboucan CR, Toth EL. High rates of the metabolic syndrome in a First Nations Community in western Canada: prevalence and determinants in adults and children. Int J Circumpolar Health. 2006 Dec; 65(5): 389-402.

58. Hunt KJ, Resendez RG, William KW, Haffner SM, Stern MP. National Cholesterol Education Program versus World Health Organization Metabolic Syndrome in relation to all-cause and cardiovascular mortality in the San Antonio Heart Study. Circulation. 2004 Sep;110:1251-7.

59. Tremblay MS, Williams JD. Secular trends in the body mass index of Canadian children. CMAJ. 2000 Nov;163(11):1429-33. 
60. Burke V, Beilin LJ, Simmer K, et al. Predictors of body mass index and associations with cardiovascular risk factors in Australian children: a prospective cohort study. Int J Obesity. 2005 Sept;29:15-23.

61. Public Health Agency of Canada, Canadian Institute for Health Information. Obesity in Canada. A joint report from the Public Health Agency of Canada and the Canadian Institute for Health Information. Ottawa $(\mathrm{ON}): 2011$.

62. Loucks EB, Rehkopf DH, Thurston RC, Kawachi I. Socioeconomic disparities in metabolic syndrome differ by gender: evidence from NHANES III. Ann Epidemiol. 2007 Jan;17(1):19-26.

63. Dallongeville J, Cottel D, Ferrières J, et al. Household income is associated with the risk of metabolic syndrome in a sex-specific manner. Diabetes Care. 2005 Feb;28(2):409-15. 